\title{
POTENSI RAWAN BANJIR KECAMATAN MUARA BANGKAHULU SEBAGAI PENUNJANG PEMBELAJARAN MATERI PEMANASAN GLOBAL DI SMPN 11 KOTA BENGKULU
}

\author{
Suherianti $^{*}$, A. Mayub ${ }^{2}$, M. Farid ${ }^{3}$ \\ ${ }^{1,2}$ Pascasarjana Pendidikan IPA FKIP Universitas Bengkulu, Bengkulu \\ ${ }^{3}$ Jurusan Fisika FMIPA Universitas Bengkulu, Bengkulu \\ *Email: suherianti14@gmail.com
}

\begin{abstract}
ABSTRAK
Dalam mencapai tujuan penelitian, pemetaan wilayah potensi banjir melalui pendekatan zonasi spasial berdasarkan elevasi, jarak dari sungai, dan jarak dari garis pantai. Data koordinat dan elevasi diperoleh langsung di lapangan menggunakan GPS Epoch ${ }^{\mathrm{TM}} 10 \mathrm{~L} 1$. Hasil penelitian ditampilkan sebagai penunjang dalam pembelajaran Pemanasan Global melalui pembelajaran berbasis masalah (PBL). Penelitian ini menggunakan metode quasi eksperimen dengan 32 peserta didik. Hasil penelitian didapat peta rawan banjir yang diklasifikasikan ke dalam 3 zona rawan banjir, yaitu zona rawan satu, zona rawan dua, dan zona rawan tiga dengan wilayah paling rawan ada pada Kelurahan Rawa Makmur, Rawa Makmur Permai, dan Beringin Raya. Implementasi penelitian pada pembelajaran menunjukkan bahwa setelah belajar menggunakan model Problem Based Learning (PBL): 1) Hasil belajar kognitif peserta didik mengalami peningkatan dengan nilai rata-rata $\mathrm{N}$-gain kelompok tinggi 0,81 (kriteria tinggi), kelompok sedang 0,60 (kriteria sedang), dan kelompok rendah 0,46 (kriteria sedang); 2) Terdapat perbedaan hasil belajar kognitif peserta didik antara kelompok tinggi, sedang dan rendah berdasarkan hasil Uji-Anava dengan nilai $\mathrm{F}_{\text {hitung }}=20,68$ lebih besar dari $\mathrm{F}_{\text {tabel }}=3,33$ pada taraf signifikansi $5 \%$.
\end{abstract}

Kata kunci: Kecamatan Muara Bangkahulu, Banjir, Rawan, Pemanasan Global, Model Problem Based Learning (PBL), Hasil belajar kognitif.

\section{PENDAHULUAN}

Indonesia merupakan negara rawan akan bencana banjir karena letak, bentuk, dan keunikan cuacanya. Muhi (2011) menyebutkan berbagai literatur termasuk Intergovermental Panel On Climate Change (IPCC) menyimpulkan bahwa peningkatan konsentrasi gas rumah kaca menyebabkan meningkatnya pemanasan global yang berakibat pada perubahan iklim global. Perubahan iklim yang ditandai dengan kenaikan suhu dan curah hujan mengakibatkan bencana (Akram, 2012). Indonesia merupakan negara ketiga penghasil gas rumah kaca terbesar (Measey, 2010). Perubahan iklim secara signifikan memperburuk terjadinya cuaca ekstrim dan banjir (Kwari et al, 2015) serta bahaya banjir bandang (Wahid, 2016); (Morita, 2014); (Emam, 2016). Frekuensi dan intensitas banjir di DAS sentral Eropa telah meningkat dalam beberapa tahun terakhir (Friesecke, 2004) terutama di daerah muara dataran rendah yang marjinal (Rilo, 2013). Daerah pesisir sangat dipengaruhi oleh perubahan iklim karena kenaikan muka air laut (Measey, 2010).

Berdasarkan topografi, kota Bengkulu berada pada elevasi antara $0-16 \mathrm{~m}$ dpl dengan $70 \%$ topografi datar dan $30 \%$ berbukit kecil dan rawa. Sebelah barat merupakan dataran rendah yang relatif sempit, dan berbatasan langsung dengan Samudera Hindia, sedangkan sebelah timur merupakan dataran tinggi berbatasan dengan pegunungan Bukit Barisan yang rentan erosi (Profil Bengkulu, 2015). Hal ini menyebabkan tempat-tempat yang terletak di lereng pegunungan yang menghadap ke barat memperoleh hujan terbesar, karena langsung menghadap Samudera Hindia, dimana angin dari arah barat atau barat daya kaya akan uap air. Curah hujan melebihi curah hujan rata-rata menyebabkan beberapa wilayah yang dekat dengan sungai dan pantai di Kota Bengkulu berpotensi banjir, salah satunya di Kecamatan 
Muara Bangkahulu (Farid, 2017) akibat dari meluapnya Sungai Air Bengkulu (Fitriyadi, 2015).

Ghozali (2015) menyatakan peningkatan populasi dan pertumbuhan perkotaan telah membuat konversi ruang terbuka yang dapat menyebabkan banjir. Penelitian senada juga menyatakan perubahan tutupan lahan di DAS Batanghari berkontribusi terhadap peningkatan frekuensi banjir di DAS Batanghari (Tarigan, 2015). Perubahan penggunaan lahan kehutanan dengan pertanian atau bahkan pemukiman akibatnya akan mengubah ekosistem lingkungan dan menyebabkan kerusakan pada elemen lingkungan yang memicu erosi dan degradasi aliran air dan kualitas, sementara modifikasi penggunaan lahan menyebabkan perubahan dalam aspek sosial, ekonomi, dan budaya (Iskandar, 2015). Perubahan tata ruang atau guna lahan lebih banyak pengaruh atau kontribusinya terhadap terjadinya banjir dibandingkan dengan pembangunan fisik pengendali banjir (Rosyidie, 2013). Tampak pada gambar 1 beberapa modifikasi penggunaan lahan menyebabkan banjir.

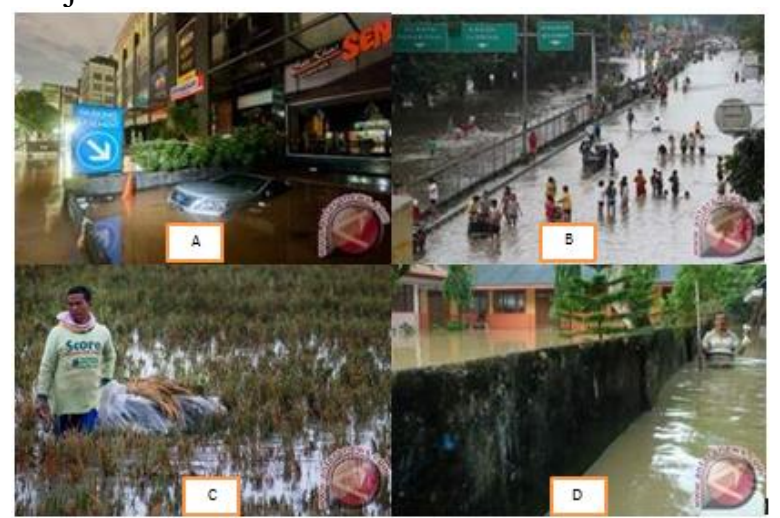

Gambar 1. Pertumbuhan perkotaan telah meningkatkan konversi ruang terbuka untuk gedung dan lahan parkir (A), untuk jalan (B), lahan pertanian (C), dan gedung sekolah (D)

Banjir juga dikatakan salah satu bencana terburuk yang paling sering terjadi sekaligus menjadi bencana alam mahal di dunia (Hapsari, 2016). Banjir terjadi telah membuat orang terkena beberapa ancaman yang menyebabkan kerusakan infrastruktur, kehilangan pekerjaan dan korban jiwa. Hasan (2012) mengkaji tentang dampak bencana banjir yang terjadi tahun 2011 terhadap perekonomian Pakistan. Hasil kajian menunjukkan bahwa banjir telah sangat merugikan ekonomi Pakistan, karena 68\% rakyat Pakistan harus tinggal di pengungsian sehingga tidak dapat beraktivitas membangkitkan perekonomian Pakistan. Huho (2014) menyimpulkan terjadi hubungan terbalik antara kuantitas bencana dengan pertumbuhan ekonomi Kenya, artinya ketika terjadi banjir maka terjadi gagal panen, berjangkitnya wabah penyakit, dan rusaknya infrastruktur. Akram (2012) mengemukakan bahwa bencana secara sigifikan menurunkan angka pertumbuhan ekonomi negara-negara Asia. Ghozali (2015) menyimpulkan bahwa kerugian akibat banjir lebih sedikit pada masyarakat yang memiliki tingkat adaptif lebih tinggi. Untuk risiko lebih kecil di masa depan, Plate (2002) menyatakan risiko banjir dapat dinilai dengan peta bahaya banjir, bahkan Friesecke (2004) menyatakan perencanaan tata ruang yang melarang pembangunan konstruksi bahkan penghapusan konversi lahan di dataran banjir. Senada dengan Plate (2002) dan Friesecke (2004), Situngkir (2014) memberi informasi agar dataran banjir tidak dikonversi semaksimal mungkin, sehingga potensi dataran banjir tetap dapat dimanfaatkan, namun tidak menambah risiko bencana banjir. Baik Ghozali (2015) maupun Plate (2002) menyatakan bahwa peta rawan banjir membantu masyarakat untuk siaga agar dampak banjir dapat diminimalisir.

Mengingat banjir yang rutin terjadi dan dataran banjir sudah menjadi pemukiman penduduk, maka menurut Rosyidie (2013) perlu pengendalian banjir dan membiasakan penduduk hidup bersama banjir. Banjir sebenarnya adalah fenomena alam yang mengisyaratkan terganggunya keseimbangan oleh kerusakan ekosistem, sehingga manusia harus memahami fenomena alam dengan cara mempelajarinya. Salah satu cabang ilmu yang mempelajari tentang fenomena alam adalah Ilmu Pengetahuan Alam (IPA). Sasikome (2015) menyimpulkan bahwa ada pengaruh penyuluhan bencana banjir terhadap kesiapsiagaan siswa SMP Katolik Soegiyo Pranoto Manado menghadapi banjir, sehingga disarankan agar sekolah melakukan pendidikan mitigasi bencana banjir secara berkala atau minimal penyuluhan bencana banjir sebagai bahan informasi dan pengembangan ilmu pengetahuan, sehingga pemahaman yang baik 
dapat berpengaruh terhadap prilaku dalam kehidupan sebagai usaha penanggulangan bencana khusus pada kesiapsiagaan.

Pemanasan Global adalah salah satu materi IPA SMP yang bertujuan agar peserta didik memahami tentang penyebab, dampak, dan upaya menanggulangi Pemanasan Global, sehingga penelitian ini dapat diimplementasi dalam pendidikan. Hasil penelitian berupa peta rawan banjir dimanfaatkan untuk menunjang pembelajaran agar peserta didik mulai terbangun sikap adaptifnya. Banjir merupakan masalah, sehingga model pembelajaran berbasis masalah $(P B L)$ tepat untuk digunakan mengingat $P B L$ dapat membantu peserta didik mengembangkan kemampuan berfikir, pemecahan masalah, keterampilan intelektual, belajar berbagai berperan orang dewasa melalui pelibatan mereka dalam pengalaman nyata sehingga menjadi pembelajar yang otonom dan mandiri (Trianto, 2010).

\section{METODE PENELITIAN}

\section{Banjir}

Menurut Paimin (2009) banjir adalah debit aliran air sungai yang secara relatif lebih besar dari biasanya/normal akibat hujan yang turun di hulu atau di suatu tempat tertentu secara terus menerus, sehingga tidak dapat ditampung oleh alur sungai yang ada, maka air melimpah keluar dan menggenangi daerah sekitarnya. Berdasarkan aspek hidrologi, air terjaga dalam siklus hidrologi, yaitu pergerakan permanen dari kelembaban di bumi yang membentuk urutan berputar dari lautan, sebagai proses penguapan (E), kemudian mengembun dan menjadi hujan (P) dan akhirnya melalui sungai mengalir sebagai debit $(\mathrm{R}=$ runoff) menuju kembali ke laut. Ketersediaan air dapat dirumuskan :

$$
\mathrm{R}=(\mathrm{P})-(\mathrm{E})-(\mathrm{A})
$$

Dalam persamaan (1) $\mathrm{R}=$ runoff $; \mathrm{P}=$ curah hujan; $\mathrm{E}=$ penguapan total dari seluruh permukaan DAS.

Apabila daerah aliran sungai suatu alur telah jenuh (mempunyai kapasitas serap dan simpan yang $\approx 0$ ), maka curah hujan akan hampir semua menjadi runoff. Pada hujan lebat di atas DAS, alur runoff akan memasuki alur dalam waktu (konsentrasi) yang cepat membentuk lonjakan hidrograf yang tajam dan menimbulkan banjir bandang di hilir. Kecepatan gerak air dari hulu akan berkurang saat mendekati laut / hilir, disebabkan topografi daerah hilir yang datar, air terhambat masuk ke laut karena sedimen atau bersamaan dengan laut pasang, maka air meluap keluar dan menggenangi lokasi disekitarnya. Sehingga lokasi yang berada di dekat sungai dan pantai, serta berelevasi rendah dapat dipastikan akan mengalami banjir.

\section{Lokasi Penelitian}

Penelitian dilakukan di wilayah Kecamatan Muara Bangkahulu seperti tampak pada gambar 2. Sedangkan lokasi implementasi penelitian dilaksanakan di SMPN 11 Kota Bengkulu yang berada pada lokasi dataran banjir.

\section{Pengumpulan Data}

Data koordinat dan elevasi diperoleh langsung melalui survei lapangan menggunakan GPS Epoch ${ }^{\mathrm{TM}} 10 \mathrm{L1}$, sedangkan jarak terdekat titik pengamatan dari sungai dan dari garis pantai menggunakan software Google Earth. Titik-titik pengamatan tampak pada gambar 2 .

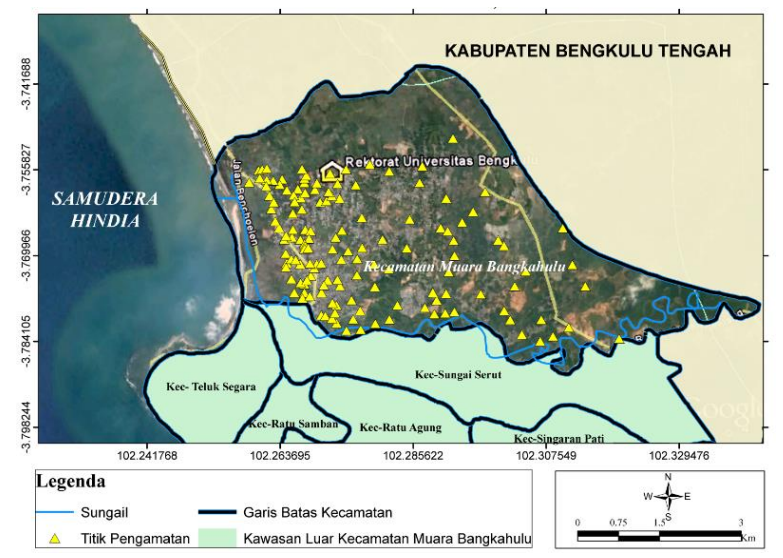

Gambar 2. Lokasi Rawan Banjir Kecamatan Muara Bangkahulu.

Untuk mengetahui peningkatan pengetahuan peserta didik, maka hasil belajar kognitif diambil dari nilai evaluasi sebelum dan setelah pembelajaran. 


\section{Pengolahan Data}

Data yang diperoleh diolah menggunakan skor : untuk elevasi 0-5m dpl skornya 10, 6-10 m dpl skornya 8, 11-15 skonya 6, dan lebih dari 15 skornya 4. Untuk jarak dari sungai : 0-100 m skornya $10,1001-200 \mathrm{~m}$ skornya $8,2001-300 \mathrm{~m}$ skonya 6, besar dari $300 \mathrm{~m} 4$. Untuk jarak dari laut : 0-200m skornya 10, 2001-400 m skornya 8 , 4001-600 skornya 6, besar dari 600 skornya 4 . Skor elevasi, skor jarak sungai dan skor jarak dari garis pantai selanjutnya dijumlah untuk masing-masing titik pengamatan untuk menentukan tingkat kerawanan banjir. Analisis data menggunakan software ArcGis 10.2 yang nantinya total skor kerawanan tertinggi sampai terendah dituangkan dalam bentuk peta seperti tampak pada gambar 3 .

Sedangkan data evaluasi pembelajaran diolah menggunakan uji $\mathrm{N}$-gain untuk melihat peningkatan hasil belajar kognitif .

\section{HASIL DAN PEMBAHASAN}

Pembagian tingkat kerawanan banjir dari 143 titik di Kecamatan Muara Bangkahulu, diketahui bahwa sekitar $8,4 \%$ zona kuning atau wilayah rawan banjir satu, $18,9 \%$ zona hijau atau wilayah rawan banjir dua, dan $72,7 \%$ zona biru yang merupakan zona aman dari banjir karena berada pada elevasi cukup tinggi dan jauh dari sungai dan garis pantai. Berikut peta tingkat kerawanan banjir.

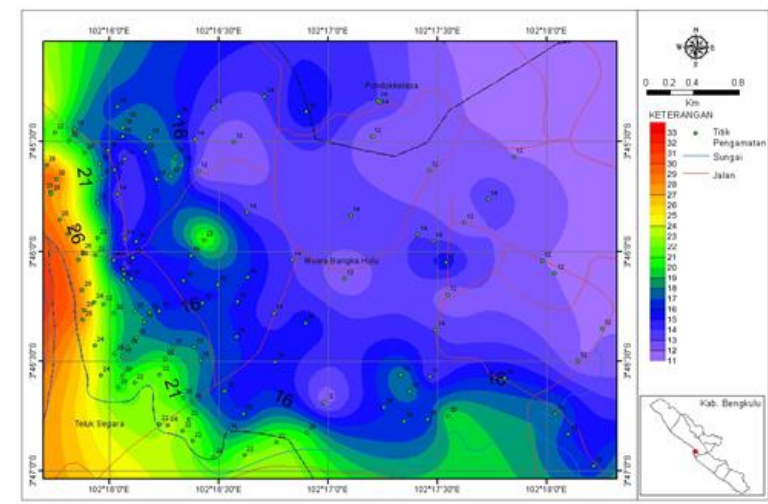

Gambar 3. Peta ancaman bahaya banjir Kecamatan Muara Bangkahulu.

Berdasarkan gambar 3 diketahui lokasi yang rawan banjir satu adalah sebagian dari kelurahan Rawa Makmur, Rawa Makmur Permai, dan
Beringin Raya. Saat hujan terjadi di bagian hulu sungai, air banyak membawa sedimen yang berasal dari tambang ataupun erosi, dan bahkan sampah yang dibuang oleh masyarakat yang nantinya akan mengendap di muara sungai yang berfungsi sebagai pelepasan atau pembuangan akhir debit sungai ke laut (Hamdani, 2014). Daerah hilir dari tambang batu bara atau emas mengalami banjir dengan frekuensi lebih tinggi dan kemungkinan meningkat selama masa 30 tahun sebagai dampak hidrologi dan sistem sungai (Wells, 2016). Permasalahan akan muncul di muara sungai, yaitu terjadi proses pendangkalan akibat adanya endapan material (sedimentasi) yang berlangsung terus menerus tiap tahun dan menyebabkan perlambatan air sungai (Hapsari, 2016). Lingkungan pantai yang berhadapan dengan rezim energi (gelombang) kuat, yang dipengaruhi oleh swell menimbulkan erosi alami pantai. Laju erosi permukaan DAS Bengkulu adalah 40,64 ton/ha/tahun atau setara dengan $2.258 \mathrm{~mm} /$ tahun dan termasuk dalam bahaya erosi tingkat II (15-60 ton/ha/tahun) atau ringan berdasarkan klasifikasi USDA. Artinya erosi permukaan DAS Bengkulu memberi kontribusi kecil terhadap sedimentasi di muara bila dibandingkan dengan transpor sedimen yang berasal dari pantai (Tunas, 2005). Hal ini menyebabkan tampang aliran menjadi kritis dan pada akhirnya akan mengganggu kelancaran proses pembuangan debit sungai ke laut terutama pada saat laut pasang naik. Ketidak lancaran proses pembuangan tersebut, dapat menyebabkan aliran balik (back water) karena proses pembendungan secara alamiah (Indradewa, 2008). Terjadinya back water ke arah hulu menyebabkan adanya genangan dan kenaikan muka air (Harlan, 2015).

Kenyataan menunjukkan setiap tahun banjir di wilayah Kecamatan Muara Bangkahulu terjadi bukan saat kemarau melainkan pada musim penghujan, sehingga dapat dikatakan banjir yang terjadi di wilayah Kecamatan Muara Bangkahulu bukan banjir rob, melainkan banjir kiriman yang bersamaan dengan laut pasang. Adanya banjir kiriman mengakibatkan luapan air sungai yang kemudian menggenangi lokasi yang berelevasi rendah serta dekat dengan sungai dan laut. Hasil penelitian ini sejalan dengan penelitian Farid (2017) bahwa daerah pesisir 
yang berpotensi banjir adalah yang terletak pada elevasi rendah, dekat dengan sungai dan laut.

Peningkatan hasil belajar kognitif setelah menggunakan model pembelajaran $P B L$ dapat dilihat pada gambar 4 .

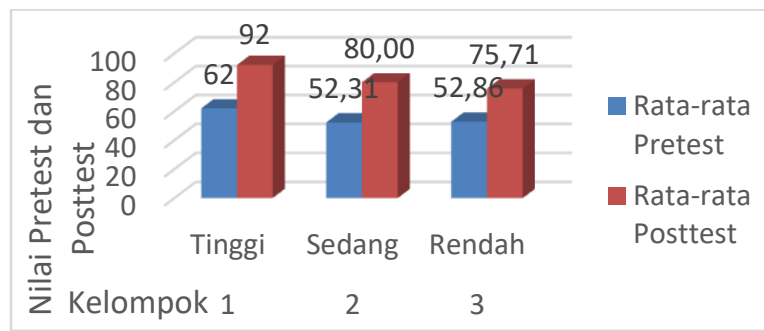

Gambar 4. Grafik nilai rata-rata tes awal dan tes akhir

Berdasarkan nilai rata-rata pretest masingmasing kelompok, kemudian dihitung nilai $\mathrm{N}$ gain setiap kelompok. Hasilnya, kelompok tinggi memiliki nilai $\mathrm{N}$-gain sebesar 0,81 (katagori tinggi), kelompok sedang sebesar 0,60 (katagori sedang), Kelompok rendah sebesar 0,46 dalam katagori sedang. Hal ini berarti bahwa kelompok tinggi memiliki peningkatan nilai yang lebih tinggi dari kelompok lainnya, sehingga dapat ditarik kesimpulan bahwa masing-masing kelompok mengalami peningkatan hasil belajar.

\section{KESIMPULAN}

Berdasarkan hasil penelitian dan pembahasan dapat ditarik kesimpulan bahwa :

1. Wilayah Kecamatan Muara Bangkahulu berada dalam 3 zona rawan banjir, yaitu rawan satu, rawan dua, dan rawan tiga dengan wilayah paling rawan ada pada wilayah Kelurahan Rawa Makmur, Rawa Makmur Permai, dan Beringin Raya.

2. Terdapat peningkatan hasil belajar kognitif peserta didik pada kelompok tinggi, sedang, dan rendah setelah belajar menggunakan model Problem Based Learning (PBL) berdasarkan nilai rata-rata $\mathrm{N}$-gain kelompok tinggi 0,81 (kriteria tinggi), kelompok sedang 0,60 (kriteria sedang), dan kelompok rendah 0,46 (kriteria sedang).

\section{DAFTAR PUSTAKA}

Akram, N. (2012). Is climate change hindering economic growth of Asian economies. Asia-Pacific Development Journal, 19(2), 1-18.

Bengkulu, D. K. P. (2015). Profil Kesehatan Provinsi Bengkulu Tahun 2015.

Farid.M, Sunarto, Suryanto.W. (2017). Investigation Of Flood Potential Areas in Bengkulu City. the 7th Annual Basic Science International Conference (BaSIC 2017), 7-8.

Fitriyadi dan Hamdani. (2015). System Performance Bengkulu River Flood Control Pump. ISSN 0215-1251 Jurnal Teknik Sumber Daya Air Vol. 1 No. 2 Juni $2015 \mid 75-84$.

Friesecke, F. (2004, October). Precautionary and Sustainable Flood Protection in GermanyStrategies and Instruments of Spatial Planning. In $3 r d$ FIG Regional Conference, Jakarta, Indonesia (pp. 3-4).

Ghozali, Achmad . (2015). A Comparative Study of Climate Change Mitigation and Adaptationon Flood Management Between Ayutthaya City (Thailand) and Samarinda City (Indonesia). CITIES 2015 International conference, Intelligent Planning Towards Smart Cities, CITIES 2015, 3-4 November 2015, Surabaya, Indonesia.

Hamdani, dkk. (2014). Analisa Daerah Rawan Banjir Menggunakan Aplikasi Sistem Informasi Geografis (Studi Kasus Pulau Bangka). Jurnal Konstruksi Sekolah Tinggi Teknologi Garut.

Hapsari, Ratih Indri dan Mohammad Zenurianto. (2016). View of Flood Disaster Management in Indonesia and the Key Solutions. American Journal of Engineering Research (AJER) e-ISSN: 2320-0847 p-ISSN : 2320-0936 Volume-5, Issue-3, 140-151.

Harlan, Dhemi, dkk. (2015). Backwater Simulation to Assess the Effects of frastructure Development Copong Weir Bridge Copong in Di Leuwigoong Garut. ISSN 0215-1251 Jurnal Teknik Sumber Daya Air Vol. 1 No. 2 - Juni 2015 | 125 134. 
Hasan, Syed Shabib (2012). Flooded Economy of Pakistan. Journal of Development and Agricultural Economics Vol. 4(13), 331338.

Huho, J. M., \& Kosonei, R. C. (2014). Understanding Extreme Climatic Events for Economic Development in Kenya. IOSR Journal of Environmental Science, Toxicology and Food Technology, 8(2), 14-24.

Indradewa, Meilani Safira. (2008). Potensi dan Upaya penanggulangan bencana banjir sungai Wolowona, nangaba dan kaliputih di kabupaten ende. Tesis.

Iskandar, Dadang dan Dede Sugandi. (2015). Flood Mitigation Efforts In The Capital Region Of Jakarta. International Journal Of Conservation Science Volume 6, Issue 4, October-December 2015: 685-696. ISSN: 2067-533X

Kwari, J. W., Ayuba, S., \& Denis, L. D. (2015). Cross case assessment of the impacts of flooding on socio-economic development and agriculture in Kogi state. International Journal, 3(8), 146-155.

Measey, M. (2010). Indonesia: a vulnerable country in the face of climate change. Global Majority E-Journal, 1(1), 31-45..

Morita, M. (2014). Flood risk impact factor for comparatively evaluating the main causes that contribute to flood risk in urban drainage areas. Water, 6(2), 253-270.

Muhi, A., Ichikawa, T., Motosugi, U., Sou, H., Nakajima, H., Sano, K., ... \& Fukushima, K. (2011). Diagnosis of colorectal hepatic metastases: Comparison of contrastenhanced CT, contrast-enhanced US, superparamagnetic iron oxide-enhanced MRI, and gadoxetic acid-enhanced MRI. Journal of Magnetic Resonance Imaging, 34(2), 326-335.

Mwape, YP. 2009. An Impact of Floods on the Socio-Economic Livelihoods of People: a Case Study of Sikaunzwe Community in Kazungula District of Zambia. Disertasi. Diakses, 01 Juni 2016.

Paimin, et al. (2009). Teknik Mitigasi Banjir dan Tanah Longsor. Balikpapan : Tropenbos International Indonesia Programme. ISBN 978-979-3145-46-4
Rafiei Emam, A., Mishra, B. K., Kumar, P., Masago, Y., \& Fukushi, K. (2016). Impact assessment of climate and land-use changes on flooding behavior in the Upper Ciliwung River, Jakarta, Indonesia. Water, 8(12), 559.

Rilo, A., Freire, P., Guerreiro, M., Fortunato, A. B., \& Taborda, R. (2013). Estuarine margins vulnerability to floods for different sea level rise and human occupation scenarios. Journal of Coastal Research, 65(sp1), 820-825.

Rosyidie, Arief. (2013). Banjir: Fakta dan Dampaknya,Serta Pengaruh dari Perubahan Guna Lahan. Jurnal Perencanaan Wilayah dan Kota, Vol. 24 No. 3, Desember 2013, 241 - 249.

Sasikome, JR, Lucky T Kumaat, Mulyadi. (2015). Pengaruh Penyuluhan Bencana Banjir Terhadap Kesiapsiagaan Siswa SMPm Katolik Soegiyo Pranoto Manado Menghadapi Banjir. ejournal Keperawatan (e-Kp) Volume 3 Nomor 2 mei 2015.

Tarigan, S. D. (2016). Land cover change and its impact on flooding frequency of Batanghari Watershed, Jambi Province, Indonesia. Procedia Environmental Sciences, 33, 386-392.

Trianto. (2010). Mendesain Model Pembelajaran Inovatif-Progresif. Jakarta : Kencana Prenada Media Grup

Tunas, I Gede. (2005). Prediksi Erosi Lahan DAS Bengkulu Dengan Sistem Informasi Geografis (SIG). Jurnal SMARTEK Vol.3, No 3.

Wahid, A., Madden, M., Khalaf, F., \& Fathy, I. (2016). Geospatial Analysis for the Determination of Hydro-Morphological Characteristics and Assessment of Flash Flood Potentiality in Arid Coastal Plains: A Case in Southwestern Sinai, Egypt. Earth Sciences Research Journal, 20(1), 1-9.

Wells, Jessie. A et al. (2016). Rising Floodwaters: Mapping Impacts and Perceptions of Flooding in Indonesian Borneo. Environ. Res. Lett. 11 